\title{
Diverticulosis de intestino delgado, hallazgo intraoperatorio.
}

Diverticulosis of the small bowell, intraoperative finding

Diverticulose do intestino delgado, achado intraoperatório

Rocío Salada ${ }^{1}$

ORCID 0000-0001-5679-4928

rocio_salada@hotmail.com

Laura Tasende ${ }^{2}$

DOI 10.31837/cir.urug/6.1.2

ORCID 0000-0001-6297-305X

lauratasende@vera.com.uy

María José Gómez del Valle 3

ORCID 0000-0003-0622-8914

2009marijo@gmail.com

Recibido: 25 de mayo de 2021

Aceptado: 25 de noviembre de 2021

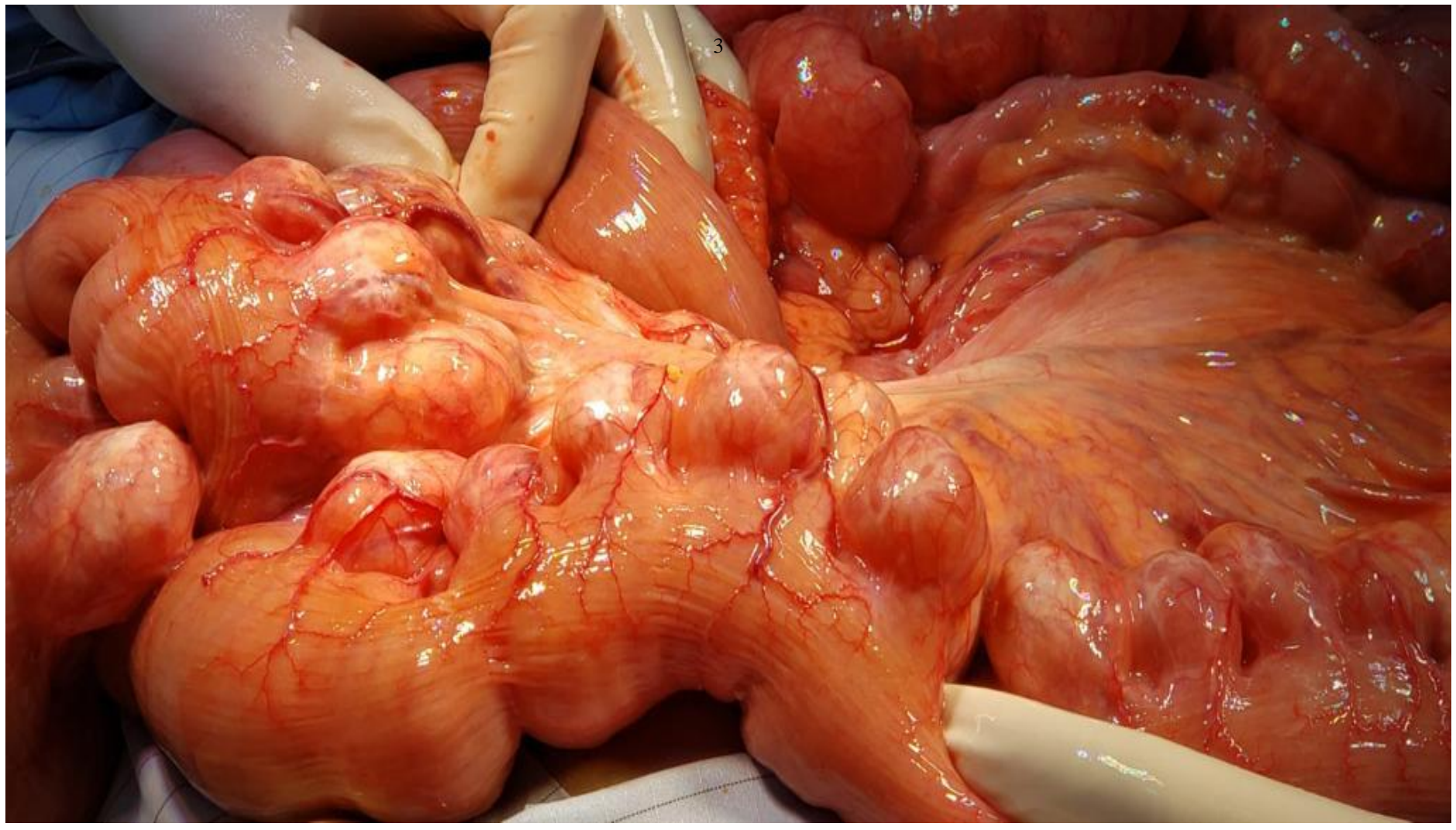

1,2,3 Departamento de Emergencia. Cirugía General. Hospital Policial "Inspector Gral. Uruguay GENTA". Montevideo, Uruguay 
La diverticulosis puede presentarse en cualquier sector del tubo digestivo. La topografía de intestino delgado es infrecuente, se presenta sobre todo a nivel del yeyuno y en un 35\% de los casos se asocia con diverticulosis colónica.

Es más frecuente en mayores de 40 años. Los divertículos van disminuyendo de tamaño y número hacia el sector distal.

Habitualmente el diagnóstico es incidental, sin embargo, pueden presentar complicaciones de las cuales se destacan por frecuencia el sangrado gastrointestinal y la diverticulitis.

Se plantea que la deficiencia de fibra dietética generaría anomalías en el peristaltismo intestinal, lo que junto con fenómenos pseudo-obstructivos y alta presión intraluminal, actuaría en áreas de debilidad focal provocando la lesión.

Presentamos el caso de una paciente de 88 años con una oclusión de colon a la cual se le realizó una cirugía de Hartmann, en el intraoperatorio se identificó divertículos de yeyuno sin elementos complicaciones. 